\title{
ROBERT R. GREENBERG WINS THE GEORGE HEVESY AWARD OF THE JOURNAL OF RADIOANALYTICAL AND NUCLEAR CHEMISTRY
}

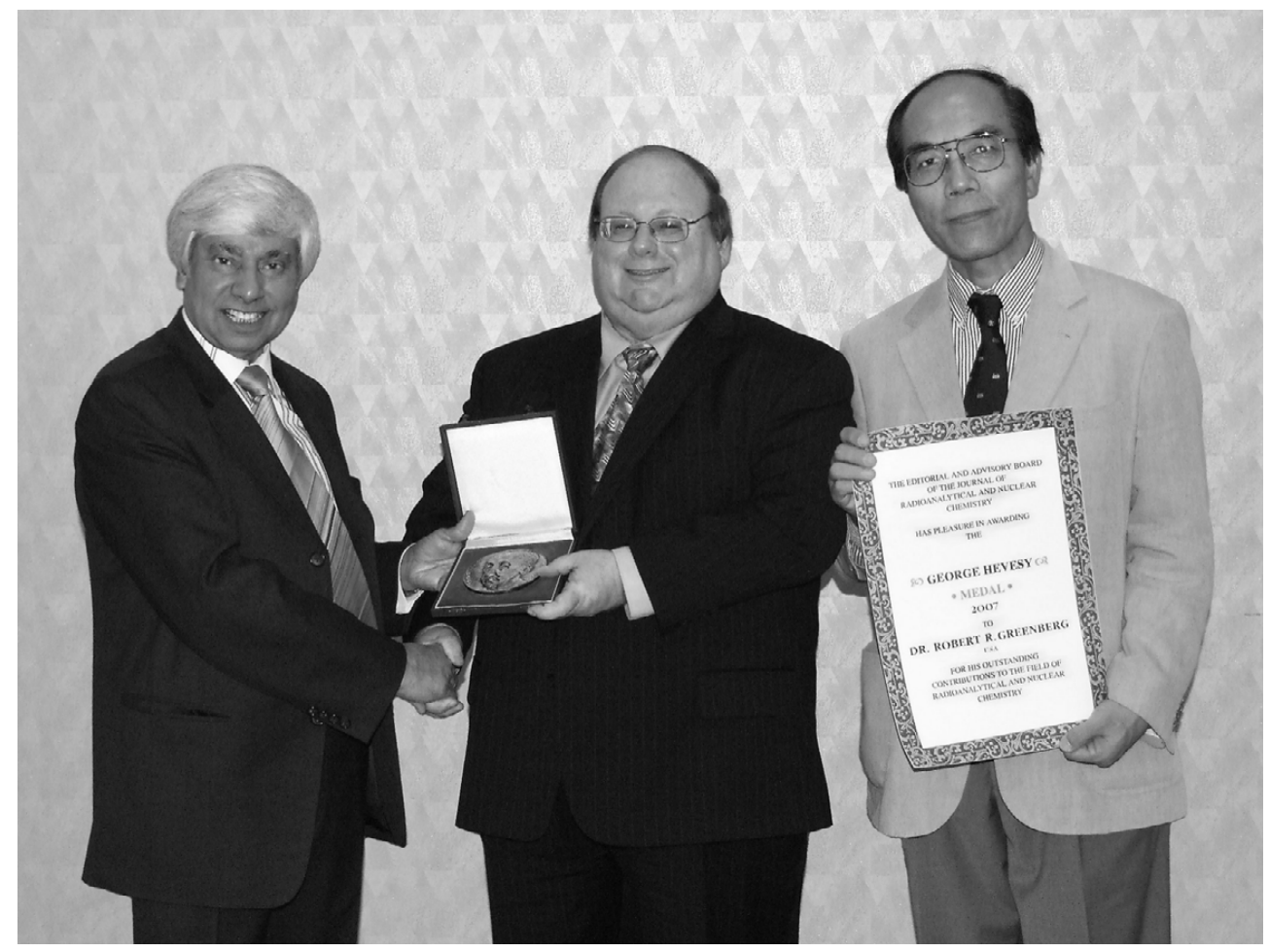

Presentation of the Hevesy Medal Award 2007 at the Twelfth International Conference on Modern Trends in Activation Analysis (MTAA-12) held at the Tokyo Metropolitan University in Hachioji, Japan, during 2007 September 16-21. Standing left to right: Prof. Dr. Amares CHATT, President of International Committee on Activation Analysis, Dr. Robert R. GreEnBERG, and Prof. Mitsuru EBIHARA, Chair, MTAA-12. 